\title{
The Influence of Oral Bacteria on Epithelial Cell Migration In Vitro
}

\author{
Alexa M. G. A. Laheij, ${ }^{1}$ Johannes J. de Soet, ${ }^{1}$ Enno C. I. Veerman, ${ }^{2}$ \\ Jan G. M. Bolscher, ${ }^{2}$ and Cor van Loveren ${ }^{1}$ \\ ${ }^{1}$ Department of Preventive Dentistry, Academic Centre for Dentistry Amsterdam (ACTA), University of Amsterdam and \\ VU University Amsterdam, Gustav Mahlerlaan 3004, 1081 LA Amsterdam, The Netherlands \\ ${ }^{2}$ Department of Oral Biochemistry, Academic Centre for Dentistry Amsterdam (ACTA), University of Amsterdam \\ and VU University Amsterdam, Gustav Mahlerlaan 3004, 1081 LA Amsterdam, The Netherlands
}

Correspondence should be addressed to Alexa M. G. A. Laheij; a.lahey@acta.nl

Received 18 June 2013; Accepted 22 September 2013

Academic Editor: Richard Logan

Copyright ( 2013 Alexa M. G. A. Laheij et al. This is an open access article distributed under the Creative Commons Attribution License, which permits unrestricted use, distribution, and reproduction in any medium, provided the original work is properly cited.

\begin{abstract}
Oral ulcerations often arise as a side effect from chemo- and radiation therapy. In a previous clinical study, Porphyromonas gingivalis was identified as a positive predictor for oral ulcerations after hematopoetic stem cell transplantation, possibly incriminating $P$. gingivalis in delayed healing of the ulcerations. Therefore, it was tested whether $P$. gingivalis and its secreted products could inhibit the migration of oral epithelial cells in an in vitro scratch assay. To compare, the oral bacteria Prevotella nigrescens, Prevotella intermedia, Tannerella forsythia, and Streptococcus mitis were included. A standardized scratch was made in a confluent layer of human oral epithelial cells. The epithelial cells were challenged with bacterial cells and with medium containing secretions of these bacteria. Closure of the scratch was measured after $17 \mathrm{~h}$ using a phase contrast microscope. P. gingivalis, P. nigrescens, and secretions of $P$. gingivalis strongly inhibited cell migration. A challenge with 1000 heat-killed bacteria versus 1 epithelial cell resulted in a relative closure of the scratch of $25 \%$ for P. gingivalis and $20 \%$ for P. nigrescens. Weaker inhibitory effects were found for the other bacteria. The results confirmed our hypothesis that the oral bacteria may be involved in delayed wound healing.
\end{abstract}

\section{Introduction}

The oral mucosa serves as a physical barrier to protect the underlying tissues from the entry of microorganisms from the oral cavity. The outer layer of the oral mucosa consists of epithelial cells [1] that are in constant contact with these oral microorganisms. Loss of integrity of the physical barrier, as in the case of ulceration, can lead to infectious complications such as bacteraemia and sepsis [2-4]. Ulcerations of the oral mucosa often occur as a side effect of chemo- and radiation therapy for cancer treatment $[5,6]$. These ulcerations are very painful and cause the patient substantial discomfort. Ulceration is an advanced stage of mucositis that has a complex pathobiology consisting of several consecutive stages, initiation, primary damage response, signal amplification, ulceration, and healing [2]. Healing consists of three phases that overlap in time, inflammation, cell proliferation and reepithelialisation, and remodeling of the tissue [7]. Cell migration is a major step in the reepithelialisation process. To study cell migration, in vitro scratch assays are commonly used with the scratched area before and after migration as the main outcome parameter [8].

The role that microorganisms play in maintaining and healing oral ulcerations after chemo- and radiation therapy is not yet clear [9]. Microorganisms are thought to intensify the inflammatory response and to further damage the mucosa [2]. In a previous prospective clinical study, we studied the relationship between bacteria that are associated with periodontitis and oral ulcerations in hematopoietic stem cell transplant (HSCT) recipients [10]. Periodontal pathogens were selected in these experiments because they demonstrated tissue damaging effects in periodontitis patients [11]. We found that the Gram-negative anaerobic 
bacterium Porphyromonas gingivalis was a positive predictor for the presence of oral ulcerations after HSCT. Parvimonas micra and Fusobacterium nucleatum possibly influenced oral ulcerations; however Prevotella intermedia and Tannerella forsythia were not predictors of oral ulcerations [10].

In the current study, we explored the hypothesis that $P$. gingivalis and its secreted products inhibit wound closure, causing delayed healing of oral ulcerations. We examined the effect of $P$. gingivalis on the migration of oral epithelial cells in an in vitro scratch assay. To compare, we included $P$. intermedia, T. forsythia, the bacteria which emerged from our previous study [10], P. nigrescens, which is closely related to $P$. intermedia and is associated with "healthy" supragingival plaque [12], and Streptococcus mitis, which is associated with oral health [13].

\section{Materials and Methods}

2.1. Epithelial Cells. The human buccal epithelial cell line HO1-N-1 was provided by the Japanese Collection of Research Bioresources (Osaka, Japan). The cells were cultured in DMEM-F12 medium (Invitrogen, Carlsbad, CA, USA) supplemented with $10 \%$ fetal calf serum (Hyclone, Logan, UT, USA), $100 \mathrm{U} / \mathrm{mL}$ penicillin, $100 \mu \mathrm{g} / \mathrm{mL}$ streptomycin, and $250 \mathrm{ng} / \mathrm{mL}$ amphotericin B (all from Sigma, St. Louis, MO, USA) in a humidified atmosphere with $5 \% \mathrm{CO}_{2}$ at $37^{\circ} \mathrm{C}$. Cells were grown until confluence, detached with $0.25 \%$ trypsinEDTA (Invitrogen), counted with a hemacytometer, and seeded in 24 -well plates at cell densities of $3-5 \cdot 10^{5}$ cells $/ \mathrm{mL}$ in DMEM-F12 medium.

2.2. Bacterial Strains and Culture. P. gingivalis W83 was cultured in Brain-Heart-Infusion (BHI; BD Difco, Le Pont de Claix, France) broth enriched with hemin $(5 \mathrm{mg} / \mathrm{L})$ and menadione $(1 \mathrm{mg} / \mathrm{L})$. P. intermedia ATCC 25611 and $P$. nigrescens ATCC 33563 were cultured in Tryptic-Soy Broth (BD Difco) supplemented with hemin $(5 \mathrm{mg} / \mathrm{L})$, menadione (1 mg/L), and glucose (56 nM). T. forsythia ATCC 43037 was cultured in BHI broth $(39 \mathrm{~g} / \mathrm{L})$ supplemented with yeast extract $(1 \mathrm{~g} / \mathrm{L})$, fetal calf serum (10\%) (HyClone), hemin $(5 \mathrm{mg} / \mathrm{L})$, menadione $(500 \mu \mathrm{g} / \mathrm{L})$, cysteine $(1 \mathrm{~g} / \mathrm{L})$, and $\mathrm{N}$ acetylmuramic acid (1.5 mL/L). S. mitis LMG 14557 was cultured in BHI broth. P. gingivalis, $P$. intermedia, $P$. nigrescens, and T. forsythia were cultured anaerobically $\left(80 \% \mathrm{~N}_{2}, 10 \% \mathrm{H}_{2}\right.$, and $10 \% \mathrm{CO}_{2}$ ), and $\mathrm{S}$. mitis was grown aerobically at $37^{\circ} \mathrm{C}$ until log-phase growth. Bacterial cultures were checked for purity by culturing and Gram staining.

2.3. Viable and Heat-Killed Bacteria. P. gingivalis viable cultures used for the scratch assay were washed twice with Dulbecco's DPBS (Invitrogen) and resuspended in keratinocyte serum-free medium (SFM, Invitrogen) at the required $\mathrm{OD}_{690}$. An $\mathrm{OD}_{690}$ of 0.1 corresponded to $5 \cdot 10^{8} \mathrm{CFU} / \mathrm{mL}$. In every scratch assay, a freshly prepared bacterial culture was used.

$P$. gingivalis, $P$. intermedia, $P$. nigrescens, and T. forsythia were killed by incubation of the bacterial cultures at $60^{\circ} \mathrm{C}$ for $60 \mathrm{~min}$. S. mitis was killed by incubation of the culture at $80^{\circ} \mathrm{C}$ for $10 \mathrm{~min}$. Killing was confirmed by absence of growth on blood agar plates. After these treatments, the cell wall of the bacteria remained intact, as was confirmed by Gram staining. After killing, the bacteria were washed twice with Dulbecco's DPBS, resuspended in SFM at the required $\mathrm{OD}_{690}$, and stored at $-80^{\circ} \mathrm{C}$ until use in the scratch assays.

2.4. Preparation of Conditioned Medium. Conditioned medium was prepared as described before [14]. P. gingivalis, $P$. nigrescens, and $S$. mitis were grown until log phase as described above. Bacteria were washed twice with DPBS and resuspended in SFM at the required $\mathrm{OD}_{690}$. Cultures were incubated anaerobically for $P$. gingivalis, $P$. nigrescens, and aerobically for $S$. mitis at $37^{\circ} \mathrm{C}$ for $6 \mathrm{~h}$. Bacteria were removed from the medium by centrifugation, and the supernatant (conditioned medium) was filter sterilized $(0.2 \mu \mathrm{m})$ (Sarstedt, Nümbrecht, Germany) and stored at $-80^{\circ} \mathrm{C}$ until use. Conditioned medium contained secreted metabolites, outer membrane vesicles, proteolytic enzymes, and signaling molecules of the bacteria $[15,16]$.

To prevent $S$. mitis from growing out in SFM, the antibiotic tetracycline was added at sub-MIC concentrations $(5 \mathrm{mg} / \mathrm{L})$. Tetracycline inhibits protein synthesis and thereby bacterial growth [17]. After incubation with S. mitis, SFM became depleted of glucose, highlighting active glucose metabolism by the bacteria [18]. In line, the $\mathrm{pH}$ decreased from 7.3 to 6.8. Both the glucose and $\mathrm{pH}$ level were restored to the original values $(6.6 \mathrm{mM}$ and $\mathrm{pH} 7.3)$ before use in the experiments. In the control SFM tetracycline was added. For every wound closure experiment, a freshly prepared batch of conditioned medium was used.

2.5. Wound Closure Assay. Scratch assays were performed as previously described with slight modifications [19]. Cells were seeded in 24 well plates at $3-5 \cdot 10^{5}$ cells/mL in DMEMF12 and grown until confluence. Cells were washed with DPBS. In each well, a scratch was made with the tip of a sterile blue pipet point (Greiner Bio-One, Alphen a/d Rijn, The Netherlands). Cells were washed twice with DPBS to remove detached cells. In each well, live or heat-killed bacteria, or conditioned medium was added. The scratch was photographed immediately and after $17 \mathrm{~h}$ with an inverted digital phase contrast microscope EVOS FL (Advanced Microscopy Group, USA), and the surface of the scratch was calculated with Photoshop CS4 (version 11.0.1, Adobe).

Closure percentage of the scratch was calculated as 100 - ((surface of the scratch at time $17 \mathrm{~h} /$ surface of the scratch at time 0$) * 100)$. Relative closure was calculated as the percentage of closure of the treatment/percentage of closure of the control (SFM). The closure of the scratch under control conditions was 1. Each treatment was performed in quintuple, and each experiment was completed on three separate occasions.

2.6. Live/Dead Staining. A PromoKine live/dead stain Kit II for cells (PromoCell GmbH, Heidelberg, Germany) was performed to ensure epithelial cell viability after infection with $P$. gingivalis. Cells were washed with DPBS. $1 \mathrm{~mL}$ of 


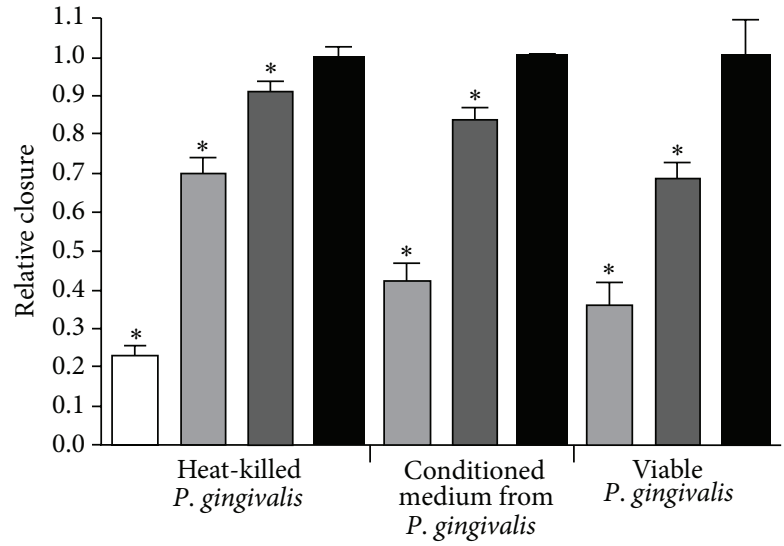

MOI 1000 MOI 100

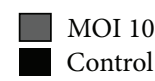

(a)

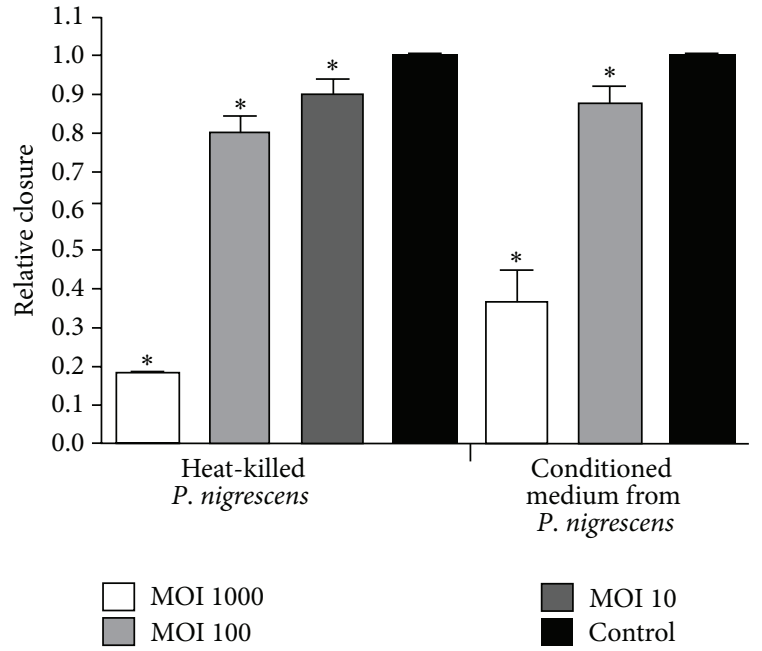

(b)

FIGURE 1: Relative closure (mean + SEM) of scratch in oral epithelial cells challenged with (a) different concentrations of heat inactivated $P$. gingivalis, conditioned medium from $P$. gingivalis, and viable $P$. gingivalis. Relative closure significantly different $(P<0.05)$ from control is marked with $*(\mathrm{~b})$ different concentrations of heat inactivated $P$. nigrescens and conditioned medium from $P$. nigrescens. Relative closure significantly different $(P<0.05)$ from control is marked with $*$.

live/dead stain with a $2 \mu \mathrm{M}$ calcein $\mathrm{AM}$ and $4 \mu \mathrm{M}$ EthDIII per well was added and incubated at room temperature for $30 \mathrm{~min}$. Cell viability was observed with an EVOS FL microscope; viable cells fluoresced brightly.

2.7. Statistical Analysis. Results of three separate experiments with the same conditions were pooled. Differences in relative closure of the scratch between bacteria and bacterial products versus control were tested with the nonparametric MannWhitney $U$ test. Statistical analyses were performed in SPSS version 20.0 (IBM SPSS, Chicago, IL, USA). A $P$ value $<0.05$ was considered statistically significant.

\section{Results}

The inhibition of oral epithelial cell migration by $P$. gingivalis is shown in Figures 1(a) and 2. In the presence of 1000 heat-killed $P$. gingivalis versus 1 epithelial cell (multiplicity of infection (MOI) of 1000) closure of the scratch relative to control conditions where the closure varied from 80 to $100 \%$ of the initial scratch, was approximately $25 \%$. At MOI 100 , relative closure of the scratch was about $70 \%$, and at MOI 10 it was about $90 \%$. For conditioned medium from P. gingivalis and viable $P$. gingivalis, detachment of epithelial cells from the bottom of the well was observed at the highest MOI tested (1000 bacteria/cell). The inhibition of relative closure of the scratch was higher when challenged with conditioned medium from $P$. gingivalis and viable $P$. gingivalis compared to when challenged with heat-killed bacteria at an MOI of 100 $(P<0.05)$. At MOI 10, conditioned medium and especially viable $P$. gingivalis produced an inhibition comparable to that of a tenfold higher number (MOI 100) of heat-killed $P$. gingivalis.
To examine if $P$. gingivalis adversely affected the viability of the epithelial cells, a live/dead staining was conducted (Figure 3). All the adhered epithelial cells exhibited a green fluorescence, indicating that their viability was maintained when they were challenged with $P$. gingivalis at MOI 1000. Moreover, the epithelial cells remained adhered to the well, they had a normal morphology, and cells around the scratch were stretching, confirming cell viability as well.

Heat-killed $P$. nigrescens inhibited cell migration at high MOI of 1000 to the same extent as $P$. gingivalis; relative closure was for approximately $20 \%$. Conditioned medium from $P$. nigrescens was less effective in inhibiting cell migration than heat inactivated bacteria $(P<0.05$, Figure $1(b))$.

Weaker inhibitory effects were found for heat-killed $P$. intermedia, T. forsythia, S. mitis, and conditioned medium from S. mitis (Figure 4). At the highest bacteria/cell ratio of heat-killed $P$. intermedia, relative closure was approximately $50 \%$, and for T. forsythia, S. mitis, and conditioned medium from S. mitis, relative closure was between 60 and $75 \%$. Heatkilled S. mitis attached firmly to the bottom of the well and formed a viscous layer in the remaining scratch after $17 \mathrm{~h}$ incubation. Despite the presence of this layer on the bottom of the well, relative closure was about $70 \%$, and the rate of cell migration did not seem to be affected.

Conditioned medium from P. intermedia and T. forsythia could not be made, and experiments with viable $P$. nigrescens, $P$. intermedia, T. forsythia, and S. mitis could not be performed due to specific needs for growth conditions.

\section{Discussion}

The aim of this study was to explore the influence of the oral bacteria $P$. gingivalis, $P$. intermedia, $P$. nigrescens, $T$. forsythia, and $S$. mitis on the migration of oral epithelial cells in an in 


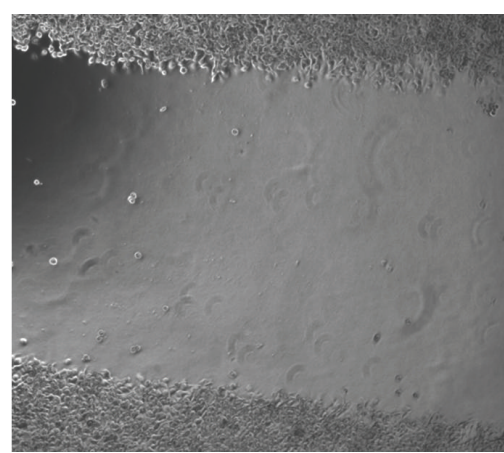

(a)

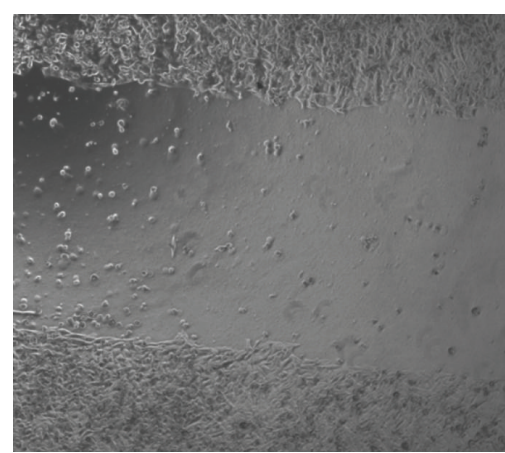

(b)

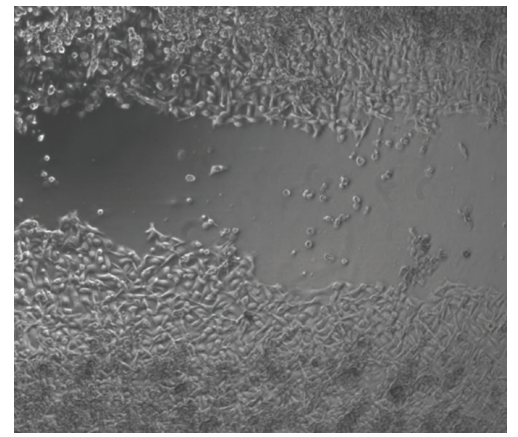

(c)

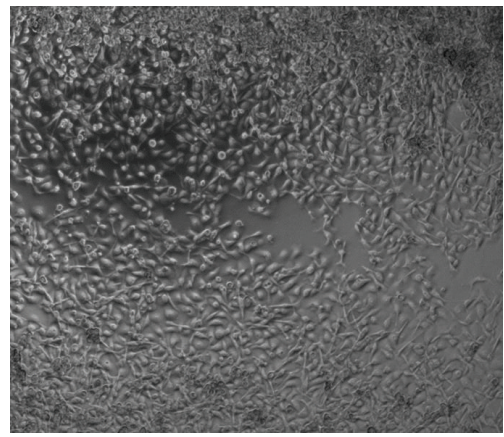

(d)

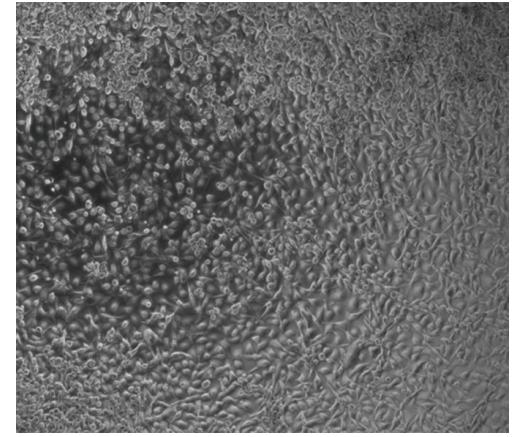

(e)

Figure 2: Representative micrographs of a challenge with different numbers of heat-killed P. gingivalis and control medium. (a) Original scratch (b)-(e) after $17 \mathrm{~h}$ incubation, (b) MOI 1000 heat-killed P. gingivalis, (c) MOI 100 heat-killed P. gingivalis, (d) MOI 10 heat-killed $P$. gingivalis, and (e) control medium.

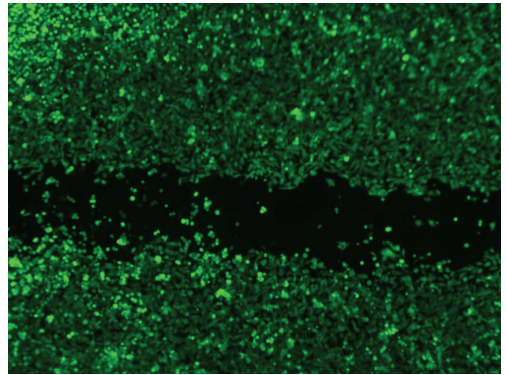

FIGURE 3: Representative example of live/dead staining of oral epithelial cells after $17 \mathrm{~h}$ challenge with heat inactivated $P$. gingivalis and control medium.

vitro scratch assay as a model for wound healing. P. gingivalis and $P$. nigrescens significantly inhibited the cell migration of oral epithelial cells. This finding supports our hypothesis that $P$. gingivalis may be involved in the delayed healing of oral ulcerations after HSCT. P. nigrescens inhibited cell migration unexpectedly. Because this bacterium is associated with plaque in a periodontally healthy situation [12], we did not anticipate such an inhibitory effect. P. intermedia, $T$. forsythia, and $S$. mitis had the lowest effects, as expected from the results of our clinical study where they were not associated with oral ulcerations [10].

The results for $P$. gingivalis are in line with two other studies that described the inhibition of cell migration by viable $P$. gingivalis $[20,21]$. To our knowledge, we are the first to report an inhibiting effect of different concentrations of heat-killed $P$. gingivalis and conditioned medium from $P$. gingivalis. Moreover, this is the only study that demonstrates the inhibition of epithelial cell migration by $P$ nigrescens, $P$. intermedia, T. forsythia, and S. mitis.

Some mechanisms of inhibition of cell migration may be excluded in our experiments, that is, epithelial cell death and physical hindrance by the bacteria occupying the scratched area. Epithelial cell viability was confirmed by live/dead staining and from the morphology (stretching) of the epithelial cells. After a challenge with the highest MOI of viable $P$. gingivalis dead and detached epithelial cells were seen. After a challenge with the other MOI's of viable $P$. gingivalis and all other conditions tested no dead and detached epithelial cells were seen. If physical hindrance by bacteria would have played an important role in inhibiting cell migration, we would have expected a strong effect of $S$. mitis, since it is very hydrophobic [22] and the bacterial cells precipitated as a sticky layer on the bottom of the well in the scratch. However, S. mitis did not inhibit epithelial cell migration effectively, and therefore, we conclude that, at least for $S$. mitis, physical hindrance does not play an important role in inhibiting cell migration.

The factors that are responsible for the inhibiting effect of $P$. gingivalis on cell migration are associated with the cell wall and are actively secreted by the bacterium. It has been reported that parts of the cell wall of $P$. gingivalis 


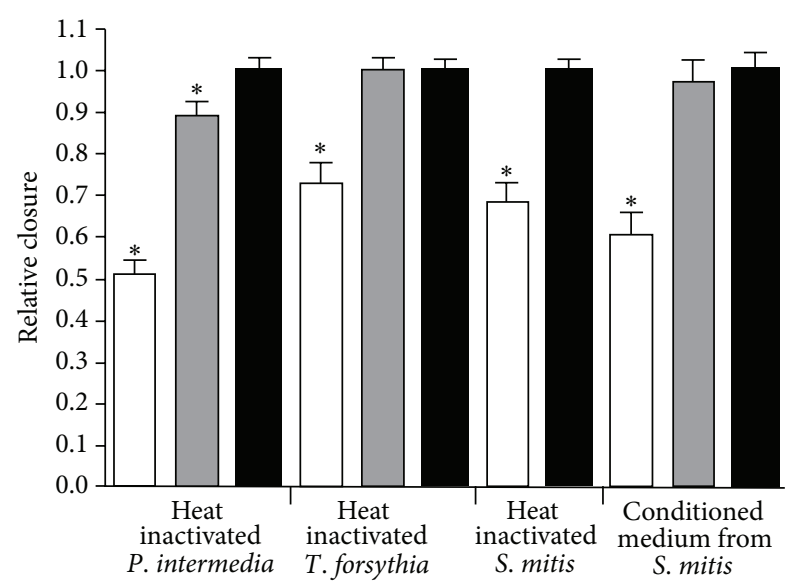

$\begin{array}{ll}\square \text { MOI } 1000 & \text { T. forsythia: } \\ \square \text { MOI } 100 & \square \text { MOI 500 } \\ \text { Control } & \square \text { MOI 50 }\end{array}$

FIGURE 4: Relative closure (mean + SEM) of scratch in oral epithelial cells challenged with different numbers of heat inactivated P. intermedia, T. forsythia, S. mitis, and conditioned medium from $S$. mitis. Relative closure significantly different $(P<0.05)$ from control is marked with $*$.

are shed as outer membrane vesicles, and therefore, the inhibiting factor in both the cellular fraction and the conditioned medium can comprise cell wall associated compounds [23]. A good candidate cell wall structure both in intact cells and in the outer membrane vesicles in Gram-negative bacteria responsible for the inhibition of cell migration is lipopolysaccharide (LPS) because of its known effects on inflammatory cytokines and bone resorption and its heat resistance $[14,24,25]$. Other virulence factors of $P$. gingivalis that are good candidates for the inhibiting effect are the cell wall-bound fimbriae and the capsular polysaccharide $[26,27]$. Heat-labile factors are responsible for an additional effect of conditioned medium and viable bacteria compared to heat-killed bacteria. LPS, the fimbriae, and the capsular polysaccharide are quite heat stable. On the other hand, the proteases that $P$. gingivalis secretes are heat labile, and therefore, this important virulence factor of $P$. gingivalis may be responsible for that additional effect.

In $P$. nigrescens, where heat-killed bacteria inhibit cell migration more than conditioned medium, LPS is probably the most important factor that causes the inhibition of cell migration. In conditioned medium from $P$. nigrescens proteases and cytotoxic end products like succinate, acetate, and ammonium [28] are present which might all inhibit cell migration. The production of outer membrane vesicles has not been reported for this bacterium. In the other tested bacteria, the causal factors are most likely present in or on the cell wall.

\section{Conclusions}

$P$. gingivalis and $P$. nigrescens and secreted products of $P$. gingivalis strongly inhibited migration of oral epithelial cells in an in vitro scratch assay. The other tested bacteria inhibited wound closure as well however to a lesser extent.

\section{Conflict of Interests}

All authors declare that there is no conflict of interests.

\section{References}

[1] C. A. Squier, “The permeability of oral mucosa," Critical Reviews in Oral Biology and Medicine, vol. 2, no. 1, pp. 13-32, 1991.

[2] S. T. Sonis, "The pathobiology of mucositis," Nature Reviews Cancer, vol. 4, pp. 277-284, 2004.

[3] J. H. Meurman, S. Pyrhönen, L. Teerenhovi, and C. Lindqvist, "Oral sources of septicaemia in patients with malignancies," Oral Oncology, vol. 33, no. 6, pp. 389-397, 1997.

[4] G. Terhes, K. Piukovics, E. Urbán, and E. Nagy, "Four cases of bacteraemia caused by Fusobacterium nucleatum in febrile, neutropenic patients," Journal of Medical Microbiology, vol. 60, no. 7, pp. 1046-1049, 2011.

[5] L. Vagliano, C. Feraut, G. Gobetto et al., "Incidence and severity of oral mucositis in patients undergoing haematopoietic SCT: results of a multicentre study," Bone Marrow Transplantation, vol. 46, no. 5, pp. 727-732, 2011.

[6] H. R. Mortensen, J. Overgaard, L. Specht et al., "Prevalence and peak incidence of acute and late normal tissue morbidity in the DAHANCA 6\&7 randomised trial with accelerated radiotherapy for head and neck cancer," Radiotherapy and Oncology, vol. 103, no. 1, pp. 69-75, 2012.

[7] A. J. Singer and R. A. Clark, "Cutaneous wound healing," The New England Journal of Medicine, vol. 341, pp. 738-746, 1999.

[8] M. A. Matthay, J.-P. Thiery, F. Lafont, M. F. Stampfer, and B. Boyer, "Transient effect of epidermal growth factor on the motility of an immortalized mammary epithelial cell line," Journal of Cell Science, vol. 106, no. 3, pp. 869-878, 1993.

[9] J. J. Napeñas, M. T. Brennan, F. K. Bahrani-Mougeot, P. C. Fox, and P. B. Lockhart, "Relationship between mucositis and changes in oral microflora during cancer chemotherapy," Oral Surgery, Oral Medicine, Oral Pathology, Oral Radiology, and Endodontics, vol. 103, no. 1, pp. 48-59, 2007.

[10] A. M. G. A. Laheij, J. J. de Soet, P. A. von dem Borne et al., "Oral bacteria and yeasts in relationship to oral ulcerations in hematopoietic stem cell transplant recipients," Supportive Care in Cancer, pp. 1-10, 2012.

[11] Z. Feng and A. Weinberg, "Role of bacteria in health and disease of periodontal tissues," Periodontology 2000, vol. 40, no. 1, pp. 50-76, 2006

[12] R. Gmür and B. Guggenheim, "Interdental supragingival plaque-a natural habitat of Actinobacillus actinomycetemcomitans, Bacteroides forsythus, Campylobacter rectus, and Prevotella nigrescens," Journal of Dental Research, vol. 73, no. 8, pp. 1421-1428, 1994.

[13] B. Nyvad and M. Kilian, "Comparison of the initial streptococcal microflora on dental enamel in caries-active and in cariesinactive individuals," Caries Research, vol. 24, no. 4, pp. 267-272, 1990.

[14] N. Scheres, T. J. de Vries, J. Brunner, W. Crielaard, M. L. Laine, and V. Everts, "Diverse effects of Porphyromonas gingivalis on human osteoclast formation," Microbial Pathogenesis, vol. 51, no. 3, pp. 149-155, 2011. 
[15] N. Bostanci and G. N. Belibasakis, "Porphyromonas gingivalis: an invasive and evasive opportunistic oral pathogen," FEMS Microbiology Letters, vol. 333, pp. 1-9, 2012.

[16] G. D. Williams and S. C. Holt, "Characteristics of the outer membrane of selected oral Bacteroides species," Canadian Journal of Microbiology, vol. 31, no. 3, pp. 238-250, 1985.

[17] J. H. Hash, M. Wishnick, and P. A. Miller, "On the mode of action of the tetracycline antibiotics in Staphylococcus aureus," The Journal of Biological Chemistry, vol. 239, pp. 2070-2078, 1964.

[18] J. J. de Soet, B. Nyvad, and M. Kilian, "Strain-related acid production by oral Streptococci," Caries Research, vol. 34, no. 6, pp. 486-490, 2000.

[19] M. J. Oudhoff, J. G. M. Bolscher, K. Nazmi et al., "Histatins are the major wound-closure stimulating factors in human saliva as identified in a cell culture assay," FASEB Journal, vol. 22, no. 11, pp. 3805-3812, 2008.

[20] E. Hintermann, S. K. Haake, U. Christen, A. Sharabi, and V. Quaranta, "Discrete proteolysis of focal contact and adherens junction components in Porphyromonas gingivalis-infected oral keratinocytes: a strategy for cell adhesion and migration disabling," Infection and Immunity, vol. 70, no. 10, pp. 58465856, 2002.

[21] I. Nakagawa, H. Inaba, T. Yamamura et al., "Invasion of epithelial cells and proteolysis of cellular focal adhesion components by distinct types of Porphyromonas gingivalis fimbriae," Infection and Immunity, vol. 74, no. 7, pp. 3773-3782, 2006.

[22] R. J. Gibbons and I. Etherden, "Comparative hydrophobicities of oral bacteria and their adherence to salivary pellicles," Infection and Immunity, vol. 41, no. 3, pp. 1190-1196, 1983.

[23] M. J. Kuehn and N. C. Kesty, "Bacterial outer membrane vesicles and the host-pathogen interaction," Genes and Development, vol. 19, no. 22, pp. 2645-2655, 2005.

[24] F. Tardif, G. Ross, and M. Rouabhia, "Gingival and dermal fibroblasts produce interleukin- $1 \beta$ converting enzyme and interleukin-1 $\beta$ but not interleukin-18 even after stimulation with lipopolysaccharide," Journal of Cellular Physiology, vol. 198, no. 1, pp. 125-132, 2004.

[25] P.-L. Wang and K. Ohura, "Porphyromonas gingivalis lipopolysaccharide signaling in gingival fibroblasts-CD14 and tolllike receptors," Critical Reviews in Oral Biology and Medicine, vol. 13, no. 2, pp. 132-142, 2002.

[26] R. D. Pathirana, N. M. O’Brien-Simpson, and E. C. Reynolds, "Host immune responses to Porphyromonas gingivalis antigens," Periodontology 2000, vol. 52, no. 1, pp. 218-237, 2010.

[27] J. Brunner, N. Scheres, N. B. El Idrissi et al., "The capsule of Porphyromonas gingivalis reduces the immune response of human gingival fibroblasts," BMC Microbiology, vol. 10, article $5,2010$.

[28] K. Saito, N. Takahashi, H. Horiuchi, and T. Yamada, "Effects of glucose on formation of cytotoxic end-products and proteolytic activity of Prevotella intermedia, Prevotella nigrescens and Porphyromonas gingivalis," Journal of Periodontal Research, vol. 36, no. 6, pp. 355-360, 2001. 


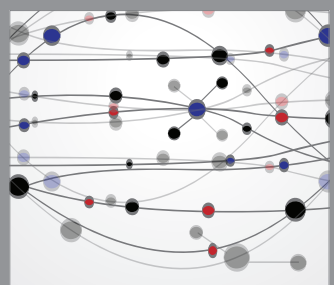

The Scientific World Journal
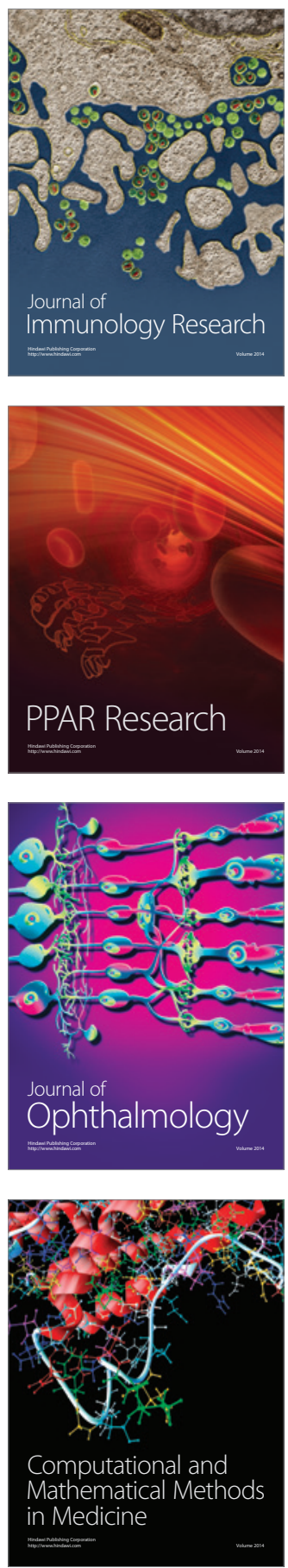

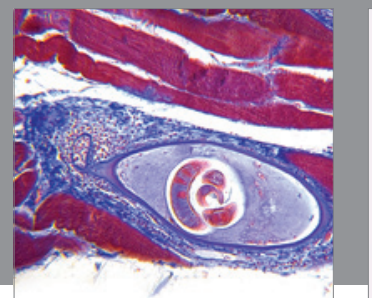

Gastroenterology

Research and Practice
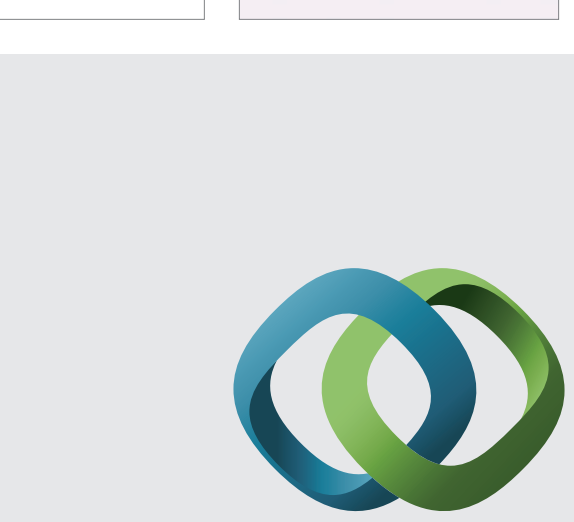

\section{Hindawi}

Submit your manuscripts at

http://www.hindawi.com
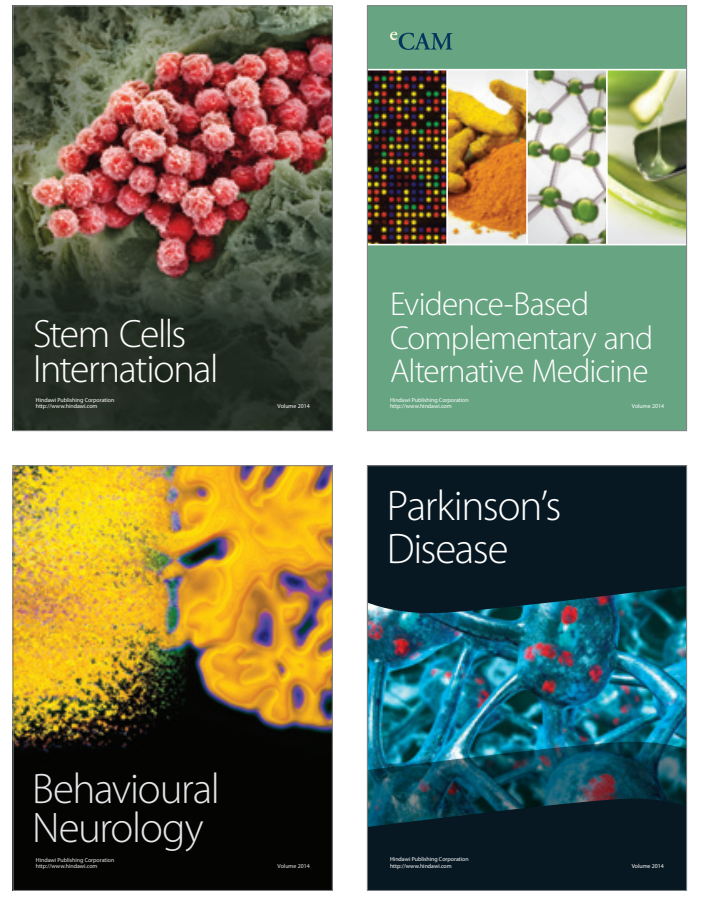
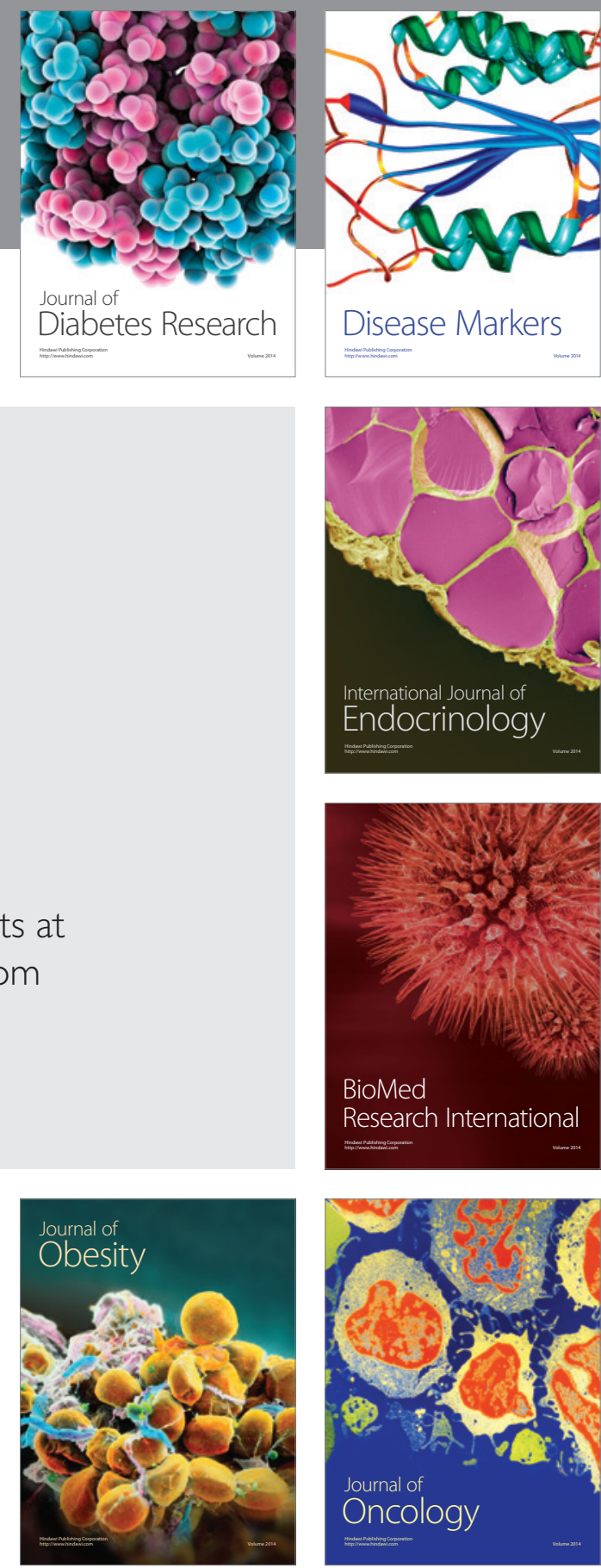

Disease Markers
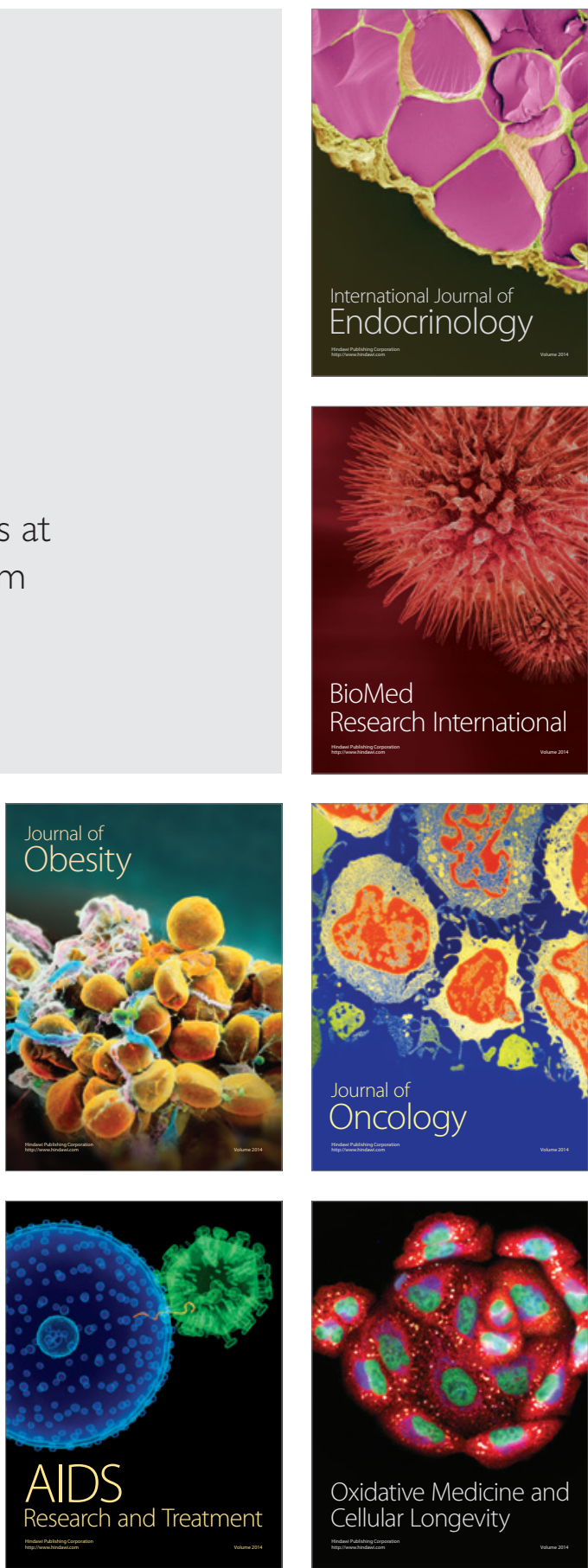